\title{
PROBLEMA DE SELWYN O CUÁNTAS HORAS HAY QUE ENTRENAR PARA LLEGAR A SER COMO SEVERIANO BALLESTEROS
}

\section{SELWYN PROBLEM OR HOW MANY HOURS YOU HAVE TO TRAIN TO BECOME AS SEVERIANO BALLESTEROS}

José Antonio Martínez Pons: Universidad de Alcalá de Henares. Madrid (España). jantonio.martinez@aol.com

\section{CURRÍCULUM VITAE}

Licenciado en Ciencias Físicas (Geofísica) por la Universidad Complutense de Madrid (España) y en Ciencias Químicas (Química física) por la UNED (España). Doctor por la Universidad de Alcalá de Henares (España) en el año 2000. Profesor de la Universidad de Alcalá de Henares en el área de Química Analítica e Ingeniería Química.

\section{RESUMEN}

¿Cuánto tiempo debe dedicar al trabajo un estudiante medio para superar los conocimientos mínimos precisos para superar sus asignaturas? ¿Qué se entiende por superar? Aprobar, promocionar, pasar el listón dentro de los parámetros tradicionales de la Universidad española. De aquí parte la reforma que el sistema educativo universitario necesita. 


\title{
PALABRAS CLAVE
}

Selwyn - Estudiante - Universidad - Reforma

\begin{abstract}
How long should a student spend at work means to overcome the minimum knowledge needed to overcome their subjects? What is meant to overcome? Condone, promote, pass the bar within the traditional parameters of the Spanish University. From here to reform the university education system needs.
\end{abstract}

\section{KEY WORDS}

Selwyn - Student - University - Reform

\section{TEXTO:}

Tengo delante de mí un formulario en el que se me pide haga una estimación del tiempo que "un estudiante medio" debe dedicar al trabajo, para adquirir los conocimientos mínimos precisos para superar mis asignaturas.

No puedo menos que recordar un viejo libro de D. Julio Palacios, su célebre "Análisis Dimensional". En él se presenta un contra-problema típico, que se atribuye a Selwyn. Dice algo así como. Sabiendo que en el juego del golf intervienen las variables: velocidad de la pelota, peso de la misma y ángulo de lanzamiento ¿Cuántas horas debe entrenar un jugador para lanzar y embocar la pelota a una distancia 1? Aplicando el análisis dimensional es fácil llegar a una expresión del tipo 
$t=\sqrt{\frac{l}{g}}, a(a)$

una expresión exacta, precisa y... ridícula, (sobre todo ridícula y sin ningún sentido).

Algo así me ocurre con eso que, con la mejor voluntad, me están pidiendo. Primero, porque no creo que exista el estudiante medio, segundo porque no creo que exista la hora de estudio media, tercero porque admitiendo que no son correctas mis dos afirmaciones anteriores y que se puede promediar, el primer parámetro que hay que fijar es donde está el hoyo, es decir ¿Qué se entiende por superar, promocionar, aprobar, pasar el listón, "probatus esse", "non essere bocciato" o como quiera decirse, es decir, qué hay que evaluar y cómo hay que evaluarlo. Por tanto me parece que por vía de aproximación, y siempre dentro de los parámetros tradicionales de la universidad española, que son los que entiendo, la magnitud es inmedible y cualquier respuesta que se dé se parecerá a la solución del problema de Selwyn.

Y aquí entro en la segunda parte de mis reflexiones.

Todo este asunto se inscribe en un propósito mucho más profundo y complejo, la reforma de la Universidad española.

No tengo ninguna duda de que nuestro sistema educativo universitario necesita una reforma en profundidad pero, cuidado, una reforma, por muy rupturista que sea, perfectamente encajable en nuestra tradición. Una mala copia de los sistemas educativos anglosajones no dejará de ser eso, una mala copia de los sistemas educativos anglosajones, de los que sacará los defectos (ya lo dijo Benavente, bienaventurados nuestros imitadores, porque de ellos serán nuestros defectos) y corruptelas, incluso las virtudes, las sacará de su contexto y se convertirán en nuevas 
corruptelas a la española, porque, por supuesto, la mayoría de vicios del sistema educativo actual seguirán ahí y al final tal convenga recordar a Lampedusa, sí, aquello de cambiémoslo todo para que todo siga igual.

Se impone primero un estudio en profundidad para ver el estado actual de nuestra universidad y su sistema que, no lo olvidemos, para bien o para mal, tiene a sus espaldas muchos siglos de historia, cosa que por razones obvias, no se puede decir de la americana. En estos siglos se han creado tradiciones y hábitos buenos, que hay que conservar y malos, que hay que corregir, pero después de un análisis serio y coherente y dando razones de peso intelectual. En resumen, que tan malo es rechazar todo lo que viene de fuera como aceptar todo lo que viene de fuera.

Hasta ahora no he visto un solo atisbo de este análisis, sólo un constante machaconeo de que hay que ir a una convergencia con Europa y dale que te doy.

Y sale una pregunta: ¿Qué es esto de la convergencia con Europa? Mucho me temo que una vez más Europa es una entelequia y una excusa. Dicen que Italia está dispuesta a renunciar a su historia universitaria y abrazará con furia de converso el nuevo método. Conocedor que soy del mundo italiano, lo dudo. Estoy seguro que Francia se apuntará a todo para acabar haciendo lo que le dé la gana. Me cuesta mucho creer que los países de influencia germánica renuncien a su método que tantos buenos resultados, al menos científicos, les han dado, así que, ¿en qué quedará Europa?

Aceptar los nuevos métodos de créditos al trabajo etc... significa un cambio radical en toda la estructura.

No concibo un sistema como el propuesto en que se siga trabajando a base de unas clases magistrales, unas prácticas de laboratorio desconectadas en el espacio y en el 
tiempo de las clases de teoría. -Sí, sé lo que estoy diciendo. ¿Tiene algún sentido hacer las prácticas en Octubre, cuando todavía ni se ha empezado a estudiar la asignatura, impartidas por el último becario del Departamento y que consisten en una serie de manejo de instrumentos desconocidos y el llenado de huecos en un guión que, por supuesto, ni se entiende, ni se puede entender?- y una prueba de examen como única forma de evaluar el progreso del estudiante que se limita a estudiar, perdón por la repetición, los quince días antes de esta prueba, siendo todo el material que utiliza unos apuntes de clase que contienen los errores del profesor, los errores del alumno y los accidentales de trasmisión. No hablo de los contenidos de estas pruebas, dudo que la mayoría superasen los más mínimos controles de adecuación y que sean un instrumento fiable de medida de la capacidad de un futuro profesional, sobre todo las pruebas de respuesta cerrada ("tipo test" por emplear el horrible barbarismo), en las que un error de concepto vale lo mismo que un error de interpretación o de lectura.

Me temo que al final todo el follón de créditos y horas se reducirá a una cosa: Reducir el bagaje cultural de los nuevos licenciados, por mucha verborrea con que esos se revista, en consecuencia, devaluar su capacitación y su título. Y no cabe duda de que se devaluarán porque, además de aligerarles la carga, los estudiantes, consecuencia de las sucesivas leyes de educación, llegan cada día a la universidad más inmaduros. No me refiero a conocimientos, lo que es obvio, sino a madurez mental. Con madurez y hábito de trabajo, los conocimientos necesarios "entran solos", sin madurez y con la idea de que todo tiene que venir resuelto desde afuera, mal vamos, ni se aprende, ni se estudia, ni se lamenta no haber aprendido, sobre todo si, por arte de birlibirloque, se "aprueba". En resumen, si reducimos la base y el tiempo real de formación, los resultados serán titulados de segunda división.

Y ahora entra Europa. Si el título de "licenciadillo" no vale y hay que competir con jóvenes formados en universidades extranjeras, será necesaria una formación 
extraordinaria, incluso no reglada y por tanto cara, y a cargo del bolsillo del estudiante o de su familia y ocurrirá, lo de siempre, el joven cuyos padres tengan dos euros y quieran invertirlos en sus hijos buscará centros privados, colegios o universidades, que den una formación de calidad, que los hay, como los hay que se limitan a vender "aprobados". Evidentemente, en cualquier proceso selectivo limpio, para estos jóvenes serán todas las ventajas. Los otros no tendrán nada que hacer frente a aquellos y no por ser "hijos de obrero" sino por estar mal preparados.

No dudo que en tres años de trabajo intensivo se adquiere mucha más formación que en siete remoloneando por la Universidad y aprobando las asignaturas por la teoría del Slalom y del paracaidista (sí aquel paracaidista que no se le abre el paracaídas y va mirando el altímetro y, cuando le quedan dos metros se consuela, sólo es un saltito). Pero debe tratarse de un trabajo serio e intensivo con dedicación exclusiva a lo que se hace y esto requiere tanto un alumnado como un profesorado concienciado y dispuesto, y con un seguimiento diario del progreso, con un trabajo personalizado y dirigido y con unos puntos departida y llegada claros.

Lo que se pretende mucho me temo será simplemente una devaluación más del nivel intelectual español. Los estudiantes a hacer lo menos posible, y a conseguir su diploma, que cada día valdrá menos, con todas las trampas que puedan, y los profesores a seguir soportando la docencia como una carga y a seguir haciendo las cosas como las han venido haciendo, hasta ahora: su investigación, lo primero y después sus clases, como las han venido dando desde hace 20 años y sus examencitos que corregirán al mes de la prueba, que tienen otras cosas mucho más perentorias que hacer.

Creo, por tanto, que antes de convergencias europeas, lo mínimo que compete a las autoridades académicas es hacer un estudio de la situación actual, analizar la capacidad de profesores y alumnos a adaptarse al sistema que se propone, analizar la 
viabilidad de este sistema y su integración en nuestra universidad y, si los resultados son negativos, pues echar mano a la imaginación y buscar una solución nuestra y dentro de nuestra idiosincrasia e historia, que conduzca realmente a una mejora de la Universidad y de la formación que esta imparte, sin olvidar nuestra rica tradición universitaria, que, aunque muy ayuna de premios Nobel (los genios, para desarrollarse, sobre todo en materia de ciencia, necesitan un caldo de cultivo social que por las razones que sean en España no se ha dado prácticamente nunca) no es tan negativa como a veces los propios universitarios creemos.

Una reforma que no cuenta con el entusiasmo o, al menos, el convencimiento del profesorado y su disponibilidad sincera a adaptarse a ella, está condenada al fracaso.

Lo que nos llevará a convergencia con Europa son unos profesionales "en promedio" sólidamente formados, no unos planes artificiales de puro artificioso e irreal, salvo, por supuesto, que en los repartos europeos nos haya tocado ser región de servicios, de camareros y flamencos, vaya. (Si son expertos en el uso del preservativo, mejor).

Por cierto y es un detalle final. Si se devalúa la moneda se devalúa toda la moneda en circulación, no la emitida a partir del momento de la devaluación.

Si se devalúan los títulos universitarios, se devalúan todos, también los nuestros y como las autoridades económicas caigan en la cuenta, me parece más probable que los "funcionarios Clase A" pasemos "Clase B" que la recíproca. Es un aviso para "navegantes". 